Cad. Est. Ling., Campinas, 53(1), Jan./Jun. 2011

\title{
ALÉM DE “OS GÊNEROS DO DISCURSO”
}

\author{
LUCAS VINÍCIO DE CARVALHO MACIEL* \\ UNICAMP
}

\begin{abstract}
RESUMO: No texto "Os gêneros do discurso" ([1952-1953]), Bakhtin discorre sobre questões concernentes aos gêneros discurso e seus elementos constitutivos. Contudo, como esse famoso ensaio é um texto conciso e inacabado, procuramos buscar, em outras leituras de Bakhtin e de seus companheiros Voloshinov e Medvedev, um aprofundamento sobre essas questões. Percorremos obras de diversas épocas, no intuito de acompanhar o desenvolvimento das discussões do Círculo de Bakhtin sobre os gêneros discursivos, a fim de tecer hipóteses sobre como os conceitos de conteúdo temático, construção composicional e estilo foram esboçados, elaborados e reelaborados em diferentes momentos até se chegar ao que se expõe no texto "Os gêneros do discurso". Pretendemos, assim, contribuir, de algum modo, para estudos que se valem desses conceitos bakhtinianos.

Palavras-chave: Gênero Discursivo, Bakhtin, Dialogismo.
\end{abstract}

\begin{abstract}
In the essay "The genres of the discourse" ([1952-1953)]), Bakhtin discusses the discursive genres and their constitutive elements. This famous essay is concise and unfinished, therefore it seems reasonable to examine other Bakhtin and his companions Voloshinov and Medvedev's texts in order to understand better these issues. In this paper, I analyze some of their works from several periods to follow near the discussions of Bakhtin's Circle about the concepts of discursive genre, thematic content, compositional structure and style, because these concepts are formulated and reformulated in different moments until the content stated in that essay is reached. I intend, in this way, contribute for the study of these bakhtinean concepts.
\end{abstract}

Key-words: Discursive genre, Bakhtin, Dialogism.

\section{INTRODUÇÃO}

As discussões desenvolvidas pelos membros do Círculo de Bakhtin acerca do gênero discursivo ganharam recentemente no Brasil um eminente espaço. Isso pode ser constatado ao se notar que as reflexões bakhtinianas, atualmente, encontram-se amplamente disseminadas, permeando desde documentos oficiais (como os Parâmetros Curriculares Nacionais, por exemplo ${ }^{1}$ ) até livros didáticos, que retomam o conceito de gênero discursivo e se servem dele como um construto basilar para reflexões teóricas e propostas de atividades pedagógicas de ensino.

O famoso texto "Os gêneros do discurso" (BAKHTIN, [1952-1953]) é que, comumente, serve de fundamento a essas assimilações das propostas bakhtinianas sobre o gênero discursivo. Diante deste quadro, discorro, neste artigo, sobre o gênero discursivo, recorrendo também a outras obras do Círculo de Bakhtin, pois parece oportuno lembrar que a complexidade do conceito de gênero discursivo pode ser mais bem captada ao expandirmos nossas leituras e percorrermos outros textos que tratam da questão.

*UNICAMP, Campinas (SP), Brasil. lucasvcmaciel@yahoo.com.br

${ }^{1}$ Ver GOMES-SANTOS, 2004. 
Antes, porém, de navegarmos pelos escritos de Bakhtin e de seus colegas, procuro contextualizar a complicada conjuntura de publicação e circulação de muitas das obras dos pensadores do Círculo de Bakhtin, já que conceitos desenvolvidos em um texto são retomados e reelaborados em outros escritos.

\section{UMA APROXIMAÇÃO AO CÍRCULO DE BAKHTIN}

No início do século XX, mais especificamente de 1919 a 1929, pensadores russos, entre os quais Mikhail Bakhtin, Valentin Voloshinov e Pavel Medvedev, formaram um grupo de estudos em que eram debatidas questões filosóficas, literárias e lingüísticas. $A$ posteriori, adotou-se a denominação de "Círculo de Bakhtin" para se referir a esse grupo de intelectuais. A denominação do grupo, em que se destaca a figura de Bakhtin, justificase pela importância de suas reflexões.

Das diversas obras desses intelectuais, a autoria de algumas ainda hoje é debatida. Oficialmente os textos "O método formal nos estudos literários" (MEDVEDEV, 1928) e "Marxismo e filosofia da linguagem" (BAKHTIN/VOLOSHINOV, 1929) foram publicados sob as assinaturas de Medvedev e de Voloshinov, respectivamente. Entretanto, a partir da segunda metade do século XX, passou-se a atribuir a Bakhtin a autoria desses textos, ao que tudo indica devido à declaração feita pelo lingüista Viatcheslav Ivanov de que as obras pertenceriam a Bakhtin, mas haviam sido editadas sob a assinatura de seus colegas. Disso decorre a atual controvérsia que paira sobre a autoria desses textos.

Opto por atribuir a Bakhtin somente as obras em que não há dúvidas quanto a sua autoria, pois como aponta Faraco:

"Bakhtin, a partir da década de 1960 e até a sua morte, teve várias oportunidades concretas de reivindicar a autoria dos textos mencionados [' $\mathrm{O}$ método formal nos estudos literários' e 'Marxismo e filosofia da linguagem'] e nunca o fez” (FARACO, 2003, p.14).

Além disso, como lembram os tradutores da versão americana de "Marxismo e filosofia da linguagem", que atribuem esse texto a Voloshinov (1929), é difícil acreditar que Bakhtin preferiu publicar sob a assinatura de seus amigos a fim de escapar da repressão pela qual passava a URSS na época. Esse fato, alegado por alguns daqueles que atribuem a Bakhtin a obra "Marxismo e filosofia da linguagem", parece incoerente, pois, segundo os tradutores americanos:

(...) ninguém convincentemente explicou porque Bakhtin em 1929 poderia ter usado o nome de seu amigo Voloshinov para Marxismo e Filosofia da Linguagem quando precisamente no mesmo ano o livro de Bakhtin sobre Dostoiévski foi publicado sob seu próprio nome e foi aceito pela crítica Soviética (... $)^{2}$ (MATEJKA e TITUNIK, 1986, p.ix, tradução nossa).

Além disso, esses tradutores, assim como Faraco (op. cit.), atestam que:

${ }^{2}(\ldots)$ no one has convincingly explained why Baxtin in 1929 would have used the name of his friend Volosinov for Marxism and the Philosophy of Language when that very same year Baxtin's book on Dostoevskij was published under his own name and was acclaimed by the Societ critics (...) 
(...) ele [Bakhtin] se recusou a assinar um depoimento com respeito à alegada autoria quando, pouco antes de sua morte, a agência de publicação oficial Soviética (VAAP) recomendou a ele assiná-lo tendo em vista a lei de direitos autorais. ${ }^{3}$ (MATEJKA e TITUNIK, 1986, p.ix, tradução nossa).

Além dos problemas de autoria, aqueles que mergulham nas obras do Círculo de Bakhtin encontram, pelo menos, mais duas dificuldades: a tradução dos textos e sua recepção no Ocidente (cf. ANDRADE, 1997; BERNARDINI, 1997; CASTRO, 1997; FARACO, 2003; LIMA, 1997). No caso brasileiro, por exemplo, somente em 2003 foi publicada uma tradução do livro "Estética da Criação Verbal" (BAKHTIN, [19521953]) (em que se encontra o ensaio "Os gêneros do discurso") do original russo para o português; antes contávamos apenas com o texto vertido para o português a partir da tradução francesa. Some-se a isso que os textos bakhtinianos chegaram ao Ocidente de forma bastante aleatória; ilustra isso que um dos primeiros textos de Bakhtin, "Para uma filosofia do ato" (1919/1921), foi traduzido para o inglês apenas em 1993 (cf. FARACO, op. cit.).

Essas questões ganham especial relevância ao se considerar que as concepções do Círculo de Bakhtin se encontram dispersas em vários textos: suas ideias são constantemente esboçadas, elaboradas e reelaboradas em diferentes estudos.

\section{O GÊNERO DISCURSIVO: UM ATO DA VIDA}

Como já colocado anteriormente, para assimilar de modo mais pleno como os membros do Círculo percebem os gêneros do discurso, parece-me razoável ir além do famoso texto "Os gêneros do discurso" (BAKHTIN, [1952-1953]), buscando em outros escritos as origens do pensamento que é condensado nesta obra de Bakhtin dos anos cinquenta.

Já em 1919, em "Para uma filosofia do ato" (BAKHTIN, 1919/1921) encontra-se algo do que posteriormente figurará nos debates bakhtinianos sobre o gênero discursivo, quando o pensador russo lança premissas filosóficas para a compreensão dos atos humanos. $\mathrm{O}$ autor atesta, naquela ocasião, que:

"No dado ponto único onde eu agora estou, ninguém jamais esteve no tempo único e no espaço único do Ser único." (op. cit., p.58).

Como somente um sujeito ocupa esse lugar único na existência, isso confere a ele uma inescapável responsabilidade, o seu "não-álibi" na existência. É esse sujeito e não outro que ocupa este lugar, independentemente de querer ou assumir esta sua responsabilidade:

"Eu, o um e o único eu, não posso em nenhum momento ser indiferente a (parar de participar de) minha inescapavelmente, obrigatoriamente única vida (...).” (BAKHTIN, 1919/1921, p.59).

${ }^{3}(\ldots)$ he [Bakhtin] refused to sign an affidavit concerning the alleged authorship when, shortly before his death, the official Soviet publishing agency (VAAP) urged him to sign for the sake of copyright law (...) 
Talvez se possa supor que a ideia de responsabilidade do homem sobre os seus atos se reflita na asserção bakhtiniana, postulada em "Os gêneros do discurso" (BAKHIN, [19521953]), de que a palavra ou oração só se torna enunciado, quando um autor a assume para si. O enunciado, assim, é um ato de responsabilidade de seu autor, pois o discurso é, antes de tudo, um ato humano na vida.

Ainda no texto sobre os gêneros do discurso, Bakhtin ([1952-1953], p.289) atesta que uma das características do enunciado é seu "elemento expressivo, isto é, a relação subjetiva emocionalmente valorativa do falante com o conteúdo do objeto e do sentido de seu enunciado". Isso porque o homem, em sua vida, não pode deixar de se relacionar axiologicamente com o mundo que o cerca; nem, por extensão, eximir-se de valorar os enunciados que profere. Já em 1919, Bakhtin (1919/1921, p.50-51) afirmara que: “Tudo que é realmente experimentado é (...) entoado, tem um tom emocional-volitivo e entra em relação efetiva comigo dentro da unidade do evento em processo que nos abrange.".

É aceitável imaginar que existem ecos dessa ideia - forjada nos anos 20 - de que o homem entra em contato com a realidade através de atos responsáveis e volitivos sobre a concepção - explicitada na década de 50 - de que o enunciado é matizado por certo tom volitivo e pertence a (está sob a responsabilidade de) determinado autor

\section{O GÊNERO DISCURSIVO: UM EVENTO SOCIAL}

Se, em 1919, Bakhtin estabelece os atos humanos como concretos e únicos, será Voloshinov, que, em 1929, investigará de maneira mais incisiva as ações humanas dentro de seu contexto social e histórico de realização. Dentre as atuações sociais do sujeito, Voloshinov volta-se especialmente às questões da linguagem em seu célebre estudo "Marxismo e filosofia da linguagem".

Para Voloshinov:

"A situação social mais imediata e o meio social mais amplo determinam completamente e, por assim dizer, a partir de seu próprio interior, a estrutura da enunciação" (BAKHTIN/VOLOSHINOV, 1929, p.117, grifo do autor).

Os atos humanos, entre os quais a realização da linguagem, ganham na abordagem de Voloshinov uma coloração marxista, através da valorização do contexto social da enunciação. $\mathrm{O}$ ato agora é o ato social; a linguagem, por extensão, é vista no âmbito da comunicação social. Para Voloshinov, a enunciação é compreendida a partir da "situação social imediata" (quem são os interlocutores, em que situação real se encontram) e do "meio social" (a que classe social pertencem esses enunciadores, qual papel ocupam na sociedade, em que época histórica se deu a enunciação). A enunciação é uma ação a ser apreendida no interior de uma interação verbal real, social e historicamente delimitada.

$\mathrm{O}$ vínculo entre meio social e enunciação é marcado por Bakhtin logo no início do texto "Os gêneros do discurso":

"Todos os diversos campos da atividade humana estão ligados ao uso da linguagem. Compreende-se perfeitamente que o caráter e as formas desse uso sejam tão multiformes quanto os campos da atividade humana (...)”. (BAKHTIN, [1952-1953], p.261). 
Ou seja, a linguagem - como qualquer ato da vida - está em função das esferas comunicativa, dos campos da atividade humana, em que se concretiza. Se vários são esses campos, é de se esperar que diversos também sejam os modos de se apropriar da linguagem, adequando-a aos eventos singulares da atuação do homem.

Na busca por um apropriado emprego da linguagem, o homem tende a formular, para cada campo de sua atividade, certas formas típicas de enunciados: os gêneros do discurso.

A proposição da linguagem como fenômeno social, trabalhada por Voloshinov e também considerada por Bakhtin, é entendida com mais propriedade se temos presente que boa parte das propostas do Círculo tinha como interlocutores diretos os formalistas russos, com quem, explícita ou veladamente, muitos dos textos do Círculo dialogam. Relacionar linguagem e contexto social é afastar-se da concepção formalista - bastante forte na época -, que tomava os enunciados literários como independentes da realidade.

Medvedev, por exemplo, censura o método formalista que restringe a apreciação literária exclusivamente aos aspectos formais, examinados sem nenhuma (ou com pouca) atenção ao tema. No estudo formalista de um poema ou de um romance, por exemplo, os aspectos temáticos são praticamente ignorados, examinando-se primordialmente os aspectos formais, composicionais, do texto. Medvedev, contudo, postula como equívoco essa separação da forma e do conteúdo de um texto, já que:

"Não há conteúdo sem forma, como não há forma sem conteúdo."4 (MEDVEDEV, 1928, p.222, tradução nossa).

Medvedev ainda enfatiza o elo entre o texto e a realidade. De sua perspectiva, cada gênero abrange à sua maneira a realidade.

Cada gênero é capaz de abarcar tão somente determinados aspectos da realidade. Cada gênero possui determinados princípios de seleção, determinadas formas de visão e de concepção da realidade, determinados graus na capacidade de abarcá-la e na profundidade de penetração nela. ${ }^{5}$

(MEDVEDEV, 1928, p.210, tradução nossa).

Portanto, para a apreciação completa do gênero, será proveitoso observar o modo singular como cada gênero se orienta para a realidade. Prosseguindo em seu texto, o autor ilustra isso com seguinte exemplo: "faz-se imperativo notar que os gêneros líricos, por exemplo, possuem os meios para dar forma conceitual à realidade e à vida que são

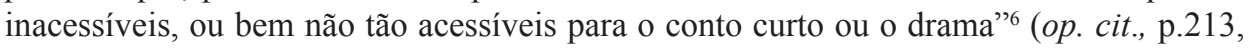
tradução nossa).

Para Medvedev, portanto, a especificidade de cada gênero se mostra, inclusive, no seu modo de relacionamento com a realidade. Encontra-se aí mais um ponto de divergência com os formalistas, que intentam uma análise do texto pelo texto, menosprezando a realidade; em decorrência disso, não podem perceber a relação singular de cada gênero com essa realidade.

\footnotetext{
${ }^{4}$ No hay contenido sin forma, como no hay forma sin contenido.

${ }^{5}$ Cada género es capaz de abarcar tan solo determinados aspectos de la realidad. Cada género posee determinados principios de selección, determinadas formas de visión y concepción de la realidad, determinados grados en la capacidad de abarcarla y en la profundidad de penetración en ella.

${ }^{6}$ (...) los géneros líricos, por ejemplo, posen los medios para dar forma conceptual a la realidad y a la vida que son inaccesibles, o bien no tan accesibles para el cuento corto o el drama.
} 
$\mathrm{O}$ embate com os formalistas encontra sua expressão mais explícita no texto "O método formal nos estudos literários" (1928) de Medvedev, mas permeia também várias obras dos demais integrantes do Círculo, pois a assunção do enunciado como evento social (portanto, atrelado à realidade) é comum a todos.

Vê-se, assim, que desde os anos vinte, aparecem nas obras de Bakhtin, de Medvedev e de Voloshinov a concepção da linguagem como um evento social, em que a situação enunciativa é vista como indispensável à compreensão do discurso.

\section{OS ELEMENTOS CONSTITUTIVOS DO GÊNERO DISCURSIVO: CONTEÚDO TEMÁTICO, ESTRUTURA COMPOSICIONAL E ESTILO}

Assim como a consideração do meio social no estudo da linguagem aparece nos escritos do Círculo pelo menos desde a década de 20, uma investigação através dos estudos de Bakhtin e de seus colegas poderá mostrar que vêm de longa data as raízes de uma das asserções bakhtinianas mais recorrentemente utilizadas em pesquisas acadêmicas e propostas de ensino. Trata-se do excerto de "Os gêneros do discurso" em que se lê que os:

(...) enunciados refletem as condições específicas e as finalidades de cada referido campo não só por seu conteúdo (temático) e pelo estilo de linguagem, ou seja, pela seleção dos recursos lexicais, fraseológicos e gramaticais da língua, mas, acima de tudo, por sua construção composicional. (BAKHTIN, [1952-1953], p. 261, grifos nossos).

Disso decorrerá que muitos estudos de viés bakhtiniano busquem observar nos textos esses três elementos: conteúdo (temático), estilo e construção composicional.

Ainda mais uma vez, quando procuramos as origens dessa postulação, podemos voltar às primeiras críticas que Bakhtin e seus companheiros lançaram contra os formalistas russos.

Iniciemos, pois, procurando as ideias pioneiras que deram origem aos conceitos de conteúdo temático e de construção composicional.

Como Medvedev, Bakhtin também se opõe à separação forma/conteúdo preconizada pelos partidários do Formalismo. Para ele, seus compatriotas formalistas são incapazes de perceber o texto literário como fenômeno social em que conteúdo e forma são indissociáveis, por não terem clara a distinção entre "forma composicional" e "forma arquitetônica". Em "O problema do conteúdo, do material e da forma na criação literária" (BAKHTIN, 1924), escrito em 1924 e publicado na coletânea de textos "Questões de literatura e de estética: a teoria do romance" (BAKHTIN, 1934-1935), o autor propõe que a forma arquitetônica seria o projeto de dizer do autor e a forma composicional a textualização desse projeto.

É a forma composicional que comumente sustenta as apreciações formalistas. Bakhtin, contudo, lembra que essa forma sempre está em função da forma arquitetônica. Em razão de seu projeto de dizer é que um autor escolhe as formas composicionais que "têm um caráter teleológico, utilitário (...) e estão sujeitas a uma avaliação puramente técnica, para determinar quão adequadamente elas realizam a tarefa arquitetônica" (BAKHTIN, 1924, p.25). 
Forma arquitetônica e forma composicional, portanto, são conceitos diferentes, mas mutuamente dependentes. A forma arquitetônica só se realiza numa forma composicional, assim como não existe forma composicional que não veicule uma forma arquitetônica. Ou seja, contrariamente à separação estanque entre forma e conteúdo proposta pelos formalistas, Bakhtin acredita que:

A principal tarefa da estética é (...) compreender o objeto estético sinteticamente, no seu todo, compreender a forma e o conteúdo em sua inter-relação essencial e necessária: compreender a forma como forma do conteúdo, e o conteúdo como conteúdo da forma (BAKHTIN, 1924, p.69).

Além dessa indissociabilidade entre forma e conteúdo já postulada por Bakhtin em 1924, a relação entre tema, forma e meio social será destacada por Voloshinov ainda anos 20:

(...) cada época e cada grupo social têm seu repertório de formas de discurso na comunicação socioideológica. A cada grupo de formas pertencentes ao mesmo gênero, isto é, cada forma de discurso social, corresponde um grupo de temas. Entre as formas de comunicação (por exemplo, relações entre os colaboradores num contexto puramente técnico), a forma de enunciação ("respostas curtas" na "linguagem de negócios") e enfim o tema, existe uma unidade orgânica que nada pode destruir. (VOLOSHINOV, 1929, p.44):

O terceiro elemento constitutivo do gênero, o estilo, também será abordado desde cedo nas obras de Bakhtin e de seus companheiros. Para os pensadores do Círculo, um ponto de interesse primordial em relação ao estilo serão as formas de citação. Voloshinov, por exemplo, dedica toda a terceira parte de "Marxismo e filosofia da linguagem" (1929) a essa questão. Bakhtin, em "O discurso no romance” (BAKHTIN, 1934-1935), também a investiga, avaliando como os discursos dos personagens se organizam no romance. $\mathrm{Ou}$ seja, a maneira como cada enunciado se apropria, citando, explicitamente ou não, outros enunciados é, para eles, uma das principais discussões teóricas sobre o estilo.

Parece-nos, assim, que até mesmo uma rápida passagem - como a empreendida neste artigo - por algumas obras pode indicar que os elementos constitutivos dos gêneros, conforme postulados por Bakhtin na década de 1950, já vinham há muito permeando, de algum modo, as discussões do Círculo.

\section{OS ELEMENTOS CONSTITUTIVOS DO GÊNERO DISCURSIVO NO DIALOGISMO}

A consideração do tema como indissociável da forma e o entendimento do estilo como modo de relacionamento com os discursos alheios são inovações trazidas pelo Círculo para análise das obras verbais. Todavia aquilo que seguramente mais se destaca nas reflexões dos membros do Círculo é o "dialogismo"; o que conduz a um original modo de se comensurar os enunciados. Segundo Bakhtin (1929/1963, p.42):

As relações dialógicas - fenômeno bem mais amplo do que as relações entre as réplicas do diálogo expresso composicionalmente - são um fenômeno quase universal, que penetra toda a linguagem humana e todas as relações e as manifestações da vida humana, em suma, tudo que tem sentido e importância. 
O dialogismo, fenômeno constitutivo da linguagem, é a relação de "diálogo" que se estabelece entre os diversos enunciados. Como num diálogo, um enunciado sempre "responde" a enunciados precedentes, bem como solicita ou espera uma resposta de enunciados futuros.

Ao enunciar, todo falante pressupõe a existência de "enunciados antecedentes - dos seus e alheios - com os quais seu enunciado entra nessas ou naquelas relações (baseiase neles, polemiza com eles, simplesmente os pressupõe já conhecidos do ouvinte)" (BAKHTIN, [1952-1953], p.272). Além de se referir (de diversos modos) a enunciados prévios, o falante não espera de seu parceiro "uma compreensão passiva, por assim dizer, que apenas duble o seu pensamento em voz alheia, mas uma resposta, uma concordância, uma participação, uma execução, etc." (BAKHTIN, op. cit., p.272).

Como o enunciado sempre estabelece alianças dialógicas com os enunciados antecedentes e futuros - que o cercam, seu tema, sua composição e seu estilo só são profundamente compreendidos no interior dessas relações.

$\mathrm{O}$ tema do enunciado necessariamente está ligado a enunciados precedentes. Conforme afirma Bakhtin ([1952-1953], p.272), o falante não é "o primeiro a ter violado o eterno silêncio do universo"; qualquer assunto já foi tema de outros enunciados, já se fez presente em outras enunciações, ninguém é o primeiro a falar daquilo. Segundo Bakhtin (1924, p.86):

(...) todo o discurso concreto (enunciação) encontra aquele objeto para o qual está voltado sempre, por assim dizer, já desacreditado, contestado, avaliado, envolvido por uma névoa escura ou, pelo contrário, iluminado pelos discursos de outrem que já falaram sobre ele.

Mais do que isso, todo falante realiza sua enunciação, em termos do tema, aguardando as réplicas (verbalizadas ou não) que suscitará. O outro, a quem a enunciação se destina, poderá se colocar frente a ela, poderá se posicionar ante esse enunciado.

Do mesmo modo, é necessário avaliar os aspectos composicionais - diversamente do que os formalistas propunham - em seu contexto de enunciação. A compreensão da forma do enunciado passa pelas relações dialógicas que ele trava com os enunciados que o cercam. Segundo Voloshinov, o "tema e a forma (...) estão indissoluvelmente ligados" já que "são as mesmas forças e as mesmas condições que dão vida a ambos". (BAKHTIN/ VOLOSHINOV, 1929, p.47). Como o tema e a forma estão unidos, é contraditório acreditar que as implicações da situação enunciativa alcancem apenas o tema, sem igualmente se refletir na forma. A forma, como parte do enunciado, também tem um passado, um presente e um futuro. Ao enunciar, o sujeito se ampara em conhecidas formas de enunciados e espera respostas, que também virão sob determinadas formas de enunciado, sob determinados gêneros do discurso.

Bakhtin ([1952-1953], p.283) afirma que:

"Se os gêneros do discurso não existissem e se nós não os dominássemos, se tivéssemos de criá-los pela primeira vez no processo do discurso, de construir livremente e pela primeira vez cada enunciado, a comunicação discursiva seria quase impossível."

Ou seja, se não houvesse alguma perenidade no gênero discursivo, a comunicação seria impraticável, pois o sujeito teria que reinventar os gêneros a cada nova enunciação. É de se imaginar que, entre os elementos mais estáveis do gênero, provavelmente, os 
aspectos composicionais tenham grande peso, pois, conforme enfatiza Bakhtin ([19521953], p.261), os gêneros são definidos "acima de tudo, por sua construção composicional". O sujeito, ao enunciar através de um gênero, vale-se de sua construção composicional típica, já que os "gêneros do discurso (...) para o indivíduo falante (...) têm significado normativo, não são criados por ele mas dados a ele” (BAKHTIN, [1952-1953], p.285). Esse caráter normativo, que o mantém relativamente estável durante o decorrer do tempo, deve-se ao dialogismo, já que a manutenção do gênero depende, em boa medida, da retomada das formas composicionais estabilizadas.

Convém também - a exemplo do tema e da estrutura composicional - apreender o terceiro elemento constitutivo do gênero, o estilo, no âmbito dos vínculos dialógicos fundados entre os enunciados. Segundo Bakhtin:

"Sem levar em conta a relação do falante com o outro e seus enunciados (presentes e antecipáveis), é impossível compreender o gênero ou estilo do discurso.” (op. cit., p.304, grifo do autor).

Isso porque, conforme lembra Voloshinov "por sua estrutura semântica e estilística, eles [os enunciados] são de fato essencialmente dialógicos (...) [pois] todo enunciado (discurso, conferência, etc.) é concebido em função de um ouvinte, ou seja, de sua compreensão e de sua resposta"7 (VOLOSHINOV, 1930, p.292, tradução nossa). É em função da sua esfera social de realização, dos seus parceiros de interlocução, que todo enunciado é arquitetado, inclusive em termos das escolhas estilísticas.

Os integrantes do Círculo não negam radicalmente a tradicional visão do estilo como escolhas que singularizam o enunciado de um determinado sujeito, mas destacam que as opções estilísticas não espelham somente os anseios do autor, pois estão ligadas à situação discursiva de enunciação e são influenciadas pelos enunciados com os quais o falante se relaciona.

O estilo compreende organicamente em si as indicações externas, a correlação de seus elementos próprios com aqueles do contexto de outrem. A política interna do estilo (combinação dos elementos) determina sua política exterior (em relação ao discurso de outrem). O discurso como que vive na fronteira de seu próprio contexto e daquele de outrem. (BAKHTIN, 1934-1935, p.92).

O falante, portanto, tem liberdade para realizar suas escolhas estilísticas, combinar internamente os elementos de seu enunciado. Contudo, é de se notar que, em função de suas escolhas estilísticas, o enunciado estabelecerá certas "políticas exteriores" e não outras. Ou seja, o estilo de um enunciado também implica determinados modos de sua apreensão e circulação nas esferas discursivas.

Assim, se por um lado, o estilo é interno ao enunciado e uma peculiaridade deste, por outro lado, não se pode deixar de notar que o estilo necessariamente estará perpassado pelas relações dialógicas estabelecidas pelo enunciado no qual se concretiza. O estilo, como componente do enunciado, também estabelece vínculos com o "discurso de outrem”.

7 (...) par leur structure sémantique et stylistique, ils [os enunciados] sont en fait essentiellement dialoguiques (...) [pois] “tout énoncé (discours, conference, etc.) est conçu en function d'un auditeur, c'est-àdire de sa compréhension et de sa réponse. 
O falante opta por este ou aquele modo de enunciar, considerando os estilos dos enunciados que retoma e supondo que as respostas a ele virão nestes ou naqueles gêneros, que guardam suas peculiares estilísticas. Ou seja, também as escolhas estilísticas estão em função do dialogismo que sustenta a enunciação.

\section{CONSIDERAÇÕES FINAIS}

Em nosso artigo, procuramos indicar, através da viagem por várias obras de Bakhtin e de seus companheiros Voloshinov e Medvedev, que as discussões sobre os gêneros discursivos podem ser aprofundadas, caso se recorra a um espectro mais amplo de textos, indo além do sintético escrito "Os gêneros do discurso" ([1952-1953]). Até mesmo por que:

"Nos planos de Bakhtin nos anos 50-70 estava o livro 'Os gêneros do discurso'; o trabalho aqui publicado [o texto "Os gêneros do discurso"] era para o autor apenas um esboço prévio dessa obra não realizada." (BEZERRA, 2003, p.447) ${ }^{8}$.

Além disso, pretendemos ilustrar que, sob a perspectiva bakhtiniana do gênero discursivo, o enunciado é um ato volitivo da vida, que se dá em certas circunstâncias sociais e históricas de enunciação.

Destacamos também que, caso se aspire a fazer uma apreciação lingüística do enunciado, será imperativo avaliar seus três elementos constituintes: o conteúdo temático da enunciação, sua estrutura composicional e seu estilo.

Mais do que isso, para compreender adequadamente esses três elementos que sustentam o enunciado, o exame linguístico do enunciado forçosamente contemplará seus elos dialógicos. Como o enunciado se forja em contato com outros enunciados, suas relações dialógicas são extremamente relevantes em sua consolidação. Assim, o tema é o tema no dialogismo, a construção composicional é a construção composicional no dialogismo e o estilo é o estilo no dialogismo.

O sujeito elege um gênero em função do lugar discursivo que ocupa, já que sua palavra, seu discurso, ocupa um dado lugar (e não outro) em uma dada esfera enunciativa. Além disso, o falante enuncia considerando - mesmo que intuitivamente - as alianças dialógicas que compõem sua palavra.

O tema, a composição e o estilo de seu enunciado não se dão espontaneamente, como um fenômeno natural. Ao contrário disso, como fruto de um acontecimento cultural, os elementos constituintes do gênero se efetivam em um evento único e singular de comunicação, obedecendo aos padrões discursivos dessa esfera enunciativa.

$\mathrm{O}$ autor proficiente tende, em sua enunciação, a considerar a melhor maneira de se abordar o tema, o modo mais apropriado de se valer (ou não) de estruturas composicionais estabilizadas para veicular sua enunciação, além de discernir entre os estilos mais adequados para os fins a que se propõe. Tende, portanto, a empregar enunciados antecedentes - seus

\footnotetext{
${ }^{8}$ Excerto do texto explicativo do tradutor Paulo Bezerra à obra "Estética da criação verbal" (BAKHTIN,
} 2003). 
e alheios - para compor sua enunciação, a não ser que queira - buscando inovar - trazer algo de novo ao âmbito do que já conhece.

Em um estudo linguístico, portanto, ao se analisar um gênero, é necessário reconhecêlo com um ato autoral da vida do falante, que elege um gênero para enunciar em função do contexto discursivo em que se encontra. Nesse gênero, o exame dos seus elementos constitutivos - conteúdo temático, construção composicional e estilo - será tanto mais adequado quanto mais presente se fizer na análise a consideração das relações dialógicas estabelecidas por esses elementos.

Ao finalizarmos este artigo, reiteramos que, ao passar por diversos textos do Círculo de Bakhtin, esperamos contribuir com algum subsídio para os que pretendem se familiarizar com as discussões bakhtinianas, bem como instigar novas reflexões naqueles que já têm vasto convívio com os debates do Círculo.

\section{REFERÊNCIAS BIBLIOGRÁFICAS}

ANDRADE, H. F. (1997). Questões de literatura e de estética: a teoria do romance. In: BRAIT, B. (Org.). Bakhtin: dialogismo e construção do sentido. $2^{\text {a }}$ ed. revista. Campinas: Editora da Unicamp, 2005, p. 335-339.

BERNARDINI, A. F. (1997). Comentários à mesa-redonda: questões de tradução na obra de Bakhtin. In: BRAIT, B. (Org.). Bakhtin: dialogismo e construção do sentido. $2^{a}$ ed. revista. Campinas: Editora da Unicamp, 2005, p. 363-365.

BAKHTIN, M. M. (1919/1921). Para uma filosofia do ato. Tradução não revisada, para fins didáticos e acadêmicos, realizada por Carlos Alberto Faraco e Cristovam Tezza. [S.I.: s.n.], [2005-2006]. . (1924). O problema do conteúdo, do material e da forma na criação literária. In: Questões de literatura e de estética: a teoria do romance. Tradução Aurora Fornoni Bernardini et al. $3^{\mathrm{a}}$ ed. São Paulo: Unesp; Hucitec, 1993.

. (1929/1963). Problemas da poética de Dostoiévski. Tradução Paulo Bezerra. 2a ed. revista. Rio de Janeiro: Forense Universitária, 1997. (1934-1935). O discurso no romance. In: Questões de literatura e de estética: a teoria do romance. Tradução Aurora Fornoni Bernardini et al. $3^{\mathrm{a}}$ ed. São Paulo: Unesp; Hucitec, 1993.

. [1952-1953]. Os gêneros do discurso. In: Estética da criação verbal. Tradução Paulo Bezerra. $4^{\mathrm{a}}$ ed. São Paulo: Martins Fontes, 2003.

BAKHTIN, M. M./ VOLOSHINOV, V. N. (1929). Marxismo e filosofia da linguagem. Tradução Michel Lahud \& Yara Frateschi Vieira. 12a ed. São Paulo: Hucitec, 2006.

BEZERRA, P. Notas ao texto "O gênero do discurso". In: BAKHTIN, M. M. Estética da criação verbal. Tradução Paulo Bezerra. 4ª ed. São Paulo: Martins Fontes, 2003.

CASTRO, E. R. (1997). O irreversível e o áporo. In: BRAIT, B. (Org.). Bakhtin: dialogismo e construção do sentido. $2^{\mathrm{a}}$ ed. revista. Campinas: Editora da Unicamp, 2005, p. 340-350.

FARACO, C. A. (2003). Linguagem e diálogo: as idéias lingüísticas do círculo de Bakhtin. $2^{\mathrm{a}}$ ed. Curitiba: Criar Edições, 2006.

GOMES-SANTOS, S. N. A questão do gênero no Brasil: teorização acadêmico-científica e normatização oficial. 2004. Dissertação (Mestrado em Lingüística Aplicada) - Instituto de Estudos da Linguagem, Universidade Estadual de Campinas, Campinas, 2008. 
CARVALHO MACIEL - Além de "Os gêneros do discurso"

LIMA, S. (1997). Tradução: um diálogo às avessas? In: BRAIT, B. (Org.). Bakhtin: dialogismo e construção do sentido. $2^{\text {a }}$ ed. revista. Campinas: Editora da Unicamp, 2005, p. 340-350.

MATEJKA, L.; TITUNIK, I. R. Translator's Preface. In: VOLOSINOV, V. N. (1929). Marxism and the philosophy of language. Tradução Ladislav Matejka e I. R. Titunik. Cambridge: Harvard University Press, 1986, p.vii-xii.

MEDVEDEV, P. N. (1928). El método formal en los estudios literarios: Introducción crítica a una poética sociológica. Tradução Tatiana Bubnova. Madrid: Alianza Editorial, 1994.

VOLOSINOV, V. N. (1929). Marxism and the Philosophy of Language. Tradução Ladislav Matejka e I. R. Titunik. Cambridge: Harvard University Press, 1986. . (1930). La structure de l'énoncé. In: TODOROV, T. (Org.). Mikhail Bakhtine: le principe dialogique. Paris: Éditions du Seuil, 1981. 